\title{
PRETREATMENT WITH POLYAMINES ALLEVIATE THE DELETERIOUS EFFECTS OF DIURON IN MAIZE LEAVES
}

\author{
NuRAn DuRmuş* and Tuba Bekírcan \\ Department of Biology, Faculty of Arts and Sciences, Recep Tayyip Erdogan University, \\ 53100 Rize, Turkey
}

(Received: March 14, 2014; accepted: June 10, 2014)

\begin{abstract}
The effects of diuron, a photosystem II inhibiting herbicide, on lipid peroxidation, photosynthetic pigments, soluble protein, proline contents and some antioxidant enzymes in maize leaves were studied and protective effects of polyamines against diuron toxicity were investigated. Diuron significantly increased lipid peroxidation, suggesting oxidative damage in the plants and proline content, while it decreased total chlorophyll, carotenoid and soluble protein levels in the leaves during the experiments. Pretreatment with polyamines statistically decreased lipid peroxidation induced by diuron and spermine (SPM) proved to be the most effective polyamine. Also, pretreatment with polyamines significantly prevented the losses of total chlorophyll, carotenoid and soluble protein induced by diuron. On the other hand, pretreatment with polyamines significantly increased proline contents of the leaves in comparison with the leaves treated with diuron. Superoxide dismutase (SOD), guaiacol peroxidase (GPX) and glutathione reductase (GR) activities increased in the leaves treated with diuron while catalase (CAT) activity decreased. Pretreatment with spermidine (SPD) did not change significantly SOD activity at 24 and $72 \mathrm{hrs}$ of diuron treatment but prevented the increase in SOD activity induced by diuron at $48 \mathrm{~h}$. However, pretreatment with SPD increased GPX activity at $24 \mathrm{~h}$ and GR activity at 48 and $72 \mathrm{hrs}$. CAT activity in the leaves pretreated with SPD was similar to that of the leaves treated with diuron. Pretreatment with SPM prevented the increase in SOD activity induced by diuron at $48 \mathrm{~h}$ but significantly increased it at $72 \mathrm{~h}$ of diuron treatment. However, pretreatment with SPM did not significantly change GPX and GR activities during the experiments but reversed the decrease in CAT activity induced by diuron at $72 \mathrm{~h}$. Pretreatment with putrescine (PUT) prevented the increase in SOD activity induced by diuron at 48 and $72 \mathrm{hrs}$ while it increased GPX and GR activities at $48 \mathrm{~h}$ of diuron treatment. Also, the decrease in CAT activity induced by diuron at $72 \mathrm{~h}$ was completely prevented by PUT. It can be concluded that pretreatment of maize leaves with polyamines reduced the damage produced by diuron and the protective effects of polyamines against diuron toxicity were closely associated with antioxidant system.
\end{abstract}

Keywords: Diuron - polyamines - antioxidant enzymes - proline - lipid peroxidation

\section{INTRODUCTION}

Diuron [3-(3,4-dichlorophenyl)-1,1-dimethylurea)] is a broad-spectrum phenylurea herbicide and algaecide used for pre- and post-emergent control of both broadleaf and grass weeds in agriculture. It is a very specific and sensitive inhibitor of photosynthesis [31].

*Corresponding author; e-mail address: durmusn@yahoo.com 
It binds to the $\mathrm{Q}_{\mathrm{B}}$-binding niche on $\mathrm{D} 1$ protein of the photosystem II complex in chloroplast thylakoid membranes, thus blocking electron transport from $Q_{A}$ to $Q_{B}$ [19]. The inability to reoxidize $\mathrm{Q}_{\mathrm{B}}$ promotes the formation of triplet state chlorophyll, which interacts with ground state oxygen to form singlet oxygen. Both triplet chlorophyll and singlet oxygen can extract hydrogen from unsaturated lipids, producing a lipid radical and initiating a chain reaction of lipid peroxidation [21].

Protective mechanisms against the production of reactive oxygen species do exist in plants. In the past years, a role for polyamines as antioxidants has been proposed [7]. It has been reported that polyamines inhibit lipid peroxidation [36, 41, 45]. Polyamines have also been described as direct free radical scavengers [15] or to function as scavengers by interacting with other molecules [10]. It is well known that polyamines are associated with the thylakoid membranes, especially, the LHCII and the PSII complex of spinach. The tetramine, spermine (SPM) was mainly found in considerable concentrations in highly purified PSII-core antenna and reaction center particles of PSII [27]. Also, Besford et al. [9] observed that exogenous polyamines supplied to osmotically stressed oat leaves retarded protein degradation, inhibited loss of chlorophyll and stabilized the thylakoid membranes. In plants, involvement of polyamines in various kinds of environmental stress has already been demonstrated $[9,16,17]$. The increase in polyamine contents of plants resulted in more tolerance to environmental stresses [43]. In recent years, some methods, such as transgenic approaches and exogenous polyamine application, have been directed towards the agricultural use of polyamines [16]. Exogenously applied polyamines have shown some protective effects in conditions of wounding [4], high temperature treatment [25], ozone damage [34], salinity [16, 42] and herbicide treatment [17]. In these studies, the relationship between polyamines and antioxidant systems has usually been determined. Although there has been little data on the action of diuron on antioxidant systems [21,37], information about the role of exogenous polyamines on diuron action in plants are completely missing. Therefore, the aim of the present work was to study the action of diuron on some oxidative stress parameters and antioxidant system in maize leaves and to investigate the protective effects of exogenous polyamines against diuron toxicity.

\section{MATERIALS AND METHODS}

\section{Plant material and treatments}

Maize (Zea mays L. cv RX 788) seeds were provided by MayAgro Seed Corporation, Bursa, Turkey. The plants were grown in plastic pots $(16 \mathrm{~cm}$ height, $18 \mathrm{~cm}$ top and $12 \mathrm{~cm}$ bottom diameter) containing soil and peat (5:1) in a greenhouse (temperature: $25 \pm 2{ }^{\circ} \mathrm{C}$ and relative humidity: $65 \pm 5 \%$ ) for 10 days. Then the pots were divided into three groups; the first group served as control, the second group were sprayed with diuron at the recommended field dose $\left(1.8 \mathrm{~kg} \mathrm{ha}^{-1}\right)$ and the other was treated with diuron after sprayed with polyamines (PUT, SPM and SPD) at $1 \mathrm{mM}$ concentrations once daily for three days. Tween 20 (0.05\%) was used as surfactant. Control plants were only 
sprayed with $0.05 \%$ Tween 20 in distilled water. Foliar samples were harvested at 24, 48 and $72 \mathrm{~h}$ after diuron application and the following analyses were performed. All treatments were repeated at least three times on different days.

\section{Lipid peroxidation}

Lipid peroxidation was measured in the term of malondialdehyde content (MDA, $\varepsilon=155 \mathrm{mmol}^{-1} \mathrm{~cm}^{-1}$ ), a product of lipid peroxidation following the method of Heath and Packer [22].

\section{Chlorophyll and carotenoid contents}

Chlorophyll and carotenoid contents were determined according to Arnon [5] and Jaspars [23], respectively.

\section{Proline content}

Proline content was determined by the ninhydrin method [6].

\section{Antioxidant enzyme assays}

Leaf samples $(0.5 \mathrm{~g})$ were homogenized in $5 \mathrm{ml}$ of cold $50 \mathrm{mM}$ potassium phosphate $\left(\mathrm{K}_{2} \mathrm{HPO}_{4}\right)$ buffer $(\mathrm{pH} 7.0)$ containing $1 \mathrm{mM}$ EDTA and $1 \%$ polyvinylpolypyrrolidone. The homogenate was centrifuged at $20,000 \times \mathrm{g}$ for $20 \mathrm{~min}$ at $4{ }^{\circ} \mathrm{C}$ and the supernatant was used for the following enzyme assay. Soluble protein content was determined according to the method of Bradford [11] with BSA as a standard.

SOD (EC 1.15.1.1) activity was based on the method of Beauchamp and Fridovich [8] as modified by Dhindsa and Matowe [14], which measures the inhibition in the photochemical reduction of nitroblue tetrazolium (NBT).

GPX (EC 1.11.1.7) activity was determined according to Urbanek et al. [40].

CAT (EC 1.11.1.6) activity was determined by following the consumption of $\mathrm{H}_{2} \mathrm{O}_{2}$ $\left(\varepsilon=39.4 \mathrm{mM}^{-1} \mathrm{~cm}^{-1}\right)$ at $240 \mathrm{~nm}$ for $3 \mathrm{~min}$ [1].

GR (EC 1.6.4.2) activity assay was based on the method of Foyer and Halliwell [20].

\section{Statistical analysis}

Variance analysis of mean values was performed by Duncan multiple comparison test using SPSS for Microsoft Windows (Ver. 10.0, SPSS Inc., USA) and statistical significance was determined at the $5 \%$ level $(\mathrm{P}<0.05)$. 


\section{RESULTS}

\section{Lipid peroxidation}

Lipid peroxidation, measured by MDA content, was significantly increased by the treatment of the leaves with diuron (Fig. 1). For example, the increment in MDA contents of the leaves treated with diuron compared to the control were determined to be $14.01 \%, 51.24 \%$ and $79.63 \%$ at 24,48 and $72 \mathrm{hrs}$, respectively. Polyamines significantly prevented lipid peroxidation increment induced by diuron. Especially, SPM was the most effective polyamine in preventing lipid peroxidation. However, SPD and PUT also significantly prevented lipid peroxidation compared to the unpretreated leaves (Fig. 1).

\section{Photosynthetic pigment contents}

Changes in photosynthetic pigment levels in maize leaves were determined for 24, 48 and $72 \mathrm{~h}$ after they were sprayed with diuron. Total chlorophyll content significantly decreased in the leaves treated with diuron (Table 1). A decrease in total chlorophyll level of the leaves pretreated with polyamines was less than that of the leaves treated

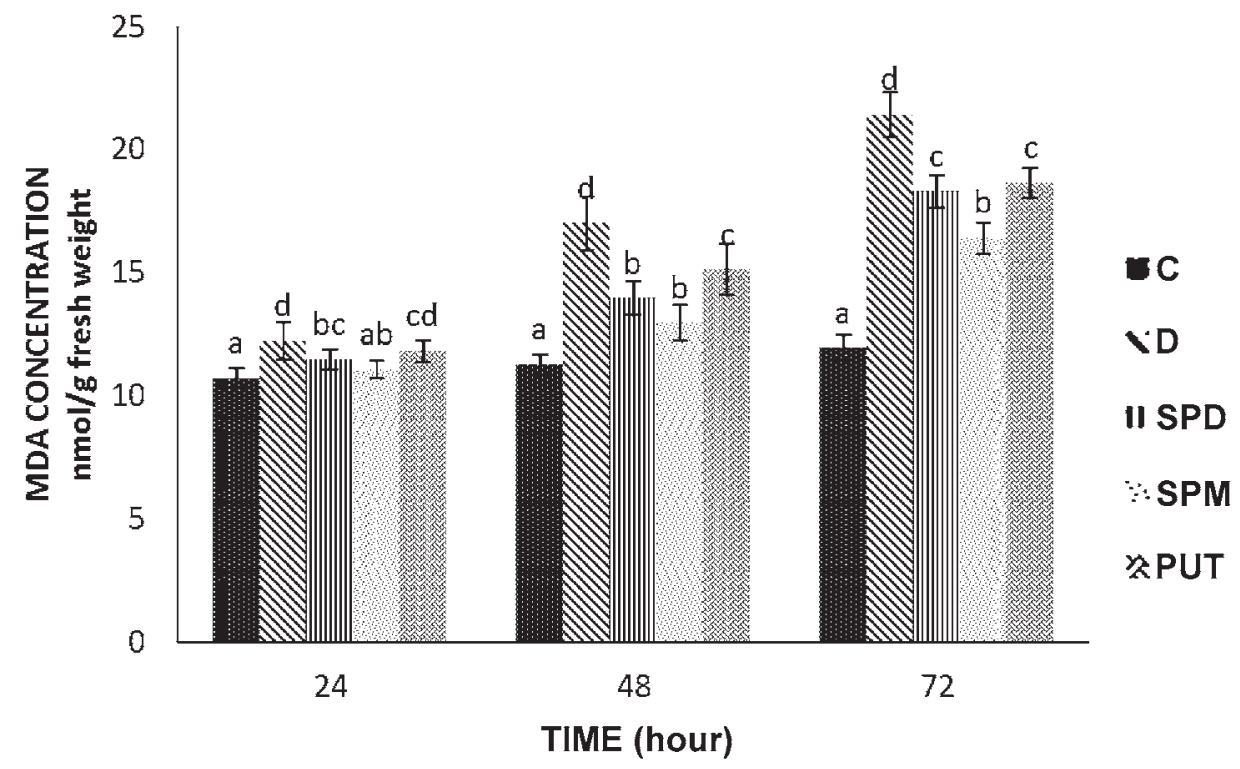

Fig. 1. Lipid peroxidation (malondialdehyde content) in maize leaves pretreated with polyamines and treated with diuron afterwards (C: Control, D: Diuron, SPD: Spermidine, SPM: Spermine, PUT: Putrescine). Vertical bars represent standard deviation of three samples. Within each hour, different letters indicate the differences among the means of three replicates. The differences between the means are significant at $P<0.05$ 
Table 1

Total chlorophyll content of the leaves pretreated with polyamines and treated with diuron afterwards

\begin{tabular}{|l|c|c|c|}
\hline \multirow{2}{*}{ Treatments } & \multicolumn{3}{|c|}{$\begin{array}{c}\text { Total chlorophyll (mg/g fresh weight) } \\
\text { Hours after diuron treatment }\end{array}$} \\
\cline { 2 - 4 } & 24 & 48 & $2.36 \pm 0.02^{\mathrm{d}}$ \\
\hline Control & $2.78 \pm 0.13^{* \mathrm{~b}}$ & $2.70 \pm 0.04^{\mathrm{e}}$ & $1.43 \pm 0.02^{\mathrm{a}}$ \\
\hline Diuron & $2.40 \pm 0.03^{\mathrm{a}}$ & $1.96 \pm 0.01^{\mathrm{a}}$ & $1.91 \pm 0.04^{\mathrm{bc}}$ \\
\hline SPD & $2.65 \pm 0.04^{\mathrm{ab}}$ & $2.24 \pm 0.02^{\mathrm{d}}$ & $1.95 \pm 0.02^{\mathrm{c}}$ \\
\hline SPM & $2.57 \pm 0.18^{\mathrm{ab}}$ & $2.16 \pm 0.03^{\mathrm{c}}$ & $1.86 \pm 0.04^{\mathrm{b}}$ \\
\hline PUT & $2.46 \pm 0.17^{\mathrm{a}}$ & $2.06 \pm 0.04^{\mathrm{b}}$ & \\
\hline
\end{tabular}

*Standard deviation of average of three replications. Values followed by different letters are significantly different from each other $(P<0.05)$ according to Duncan's test.

with only diuron. That is, polyamines significantly retarded chlorophyll degradation induced by diuron. SPM was found to be the most effective polyamine. After $72 \mathrm{~h}$ of treatment, total chlorophyll content decreased by $39.4 \%$ in the leaves treated with diuron compared to the control, while it was $17.37 \%$ in the leaves pretreated with SPM. Also, carotenoid content of the leaves treated with diuron decreased significantly (Table 2). After $72 \mathrm{~h}$ of treatment, the loss of carotenoid content was $46.15 \%$ in the leaves treated with diuron compared to the control. Carotenoid loss was significantly prevented by SPD and SPM pretreatments. It was found that carotenoid content of the leaves pretreated with SPD and SPM decreased by $23.07 \%$ and $26.92 \%$, respectively. Also, carotenoid level of the leaves pretreated with PUT was higher than that of unpretreated leaves.

Table 2

Carotenoid content of the leaves pretreated with polyamines and treated with diuron afterwards

\begin{tabular}{|l|c|c|c|}
\hline \multirow{2}{*}{ Treatments } & \multicolumn{3}{|c|}{$\begin{array}{c}\text { Carotenoid content (mg/g fresh weight) } \\
\text { Hours after diuron treatment }\end{array}$} \\
\cline { 2 - 4 } & 24 & 48 & 72 \\
\hline Control & $0.28 \pm 0.005^{* \mathrm{c}}$ & $0.26 \pm 0.005^{\mathrm{c}}$ & $0.26 \pm 0.01^{\mathrm{d}}$ \\
\hline Diuron & $0.20 \pm 0.01^{\mathrm{a}}$ & $0.17 \pm 0.005^{\mathrm{a}}$ & $0.14 \pm 0.005^{\mathrm{a}}$ \\
\hline SPD & $0.26 \pm 0.01^{\mathrm{bc}}$ & $0.23 \pm 0.02^{\mathrm{b}}$ & $0.20 \pm 0.005^{\mathrm{c}}$ \\
\hline SPM & $0.24 \pm 0.005^{\mathrm{b}}$ & $0.22 \pm 0.01^{\mathrm{b}}$ & $0.19 \pm 0.005^{\mathrm{c}}$ \\
\hline PUT & $0.21 \pm 0.02^{\mathrm{a}}$ & $0.19 \pm 0.005^{\mathrm{a}}$ & $0.17 \pm 0.005^{\mathrm{b}}$ \\
\hline
\end{tabular}

* Standard deviation of average of three replications. Values followed by different letters are significantly different from each other $(P<0.05)$ according to Duncan's test. 


\section{Soluble protein content}

As can be seen in Table 3, soluble protein content significantly decreased after diuron treatment. A decrease in soluble protein level induced by diuron was observed after $24 \mathrm{~h}$ of treatment. The loss in soluble protein content was $27.39 \%$ in the leaves treated with diuron for $72 \mathrm{~h}$ compared to control. Pretreatment with SPD, SPM and PUT prevented the loss of soluble protein induced by diuron at $24 \mathrm{~h}$ of treatment. Pretreatment with SPD was not effective at 48 and $72 \mathrm{hrs}$ of diuron treatment. However, pretreatment with SPM and PUT, respectively, was effective in preventing the loss of soluble protein at 48 and $72 \mathrm{hrs}$ of diuron treatment.

Table 3

Soluble protein content of the leaves pretreated with polyamines and treated with diuron afterwards

\begin{tabular}{|l|c|c|c|}
\hline \multirow{2}{*}{ Treatments } & \multicolumn{3}{|c|}{$\begin{array}{c}\text { Soluble protein (mg/g fresh weight) } \\
\text { Hours after diuron treatment }\end{array}$} \\
\cline { 2 - 4 } & 24 & 48 & 72 \\
\hline Control & $6.49 \pm 0.37^{* \mathrm{~b}}$ & $6.24 \pm 0.70^{\mathrm{b}}$ & $6.17 \pm 0.24^{\mathrm{c}}$ \\
\hline Diuron & $5.29 \pm 0.24^{\mathrm{a}}$ & $5.20 \pm 0.13^{\mathrm{a}}$ & $4.48 \pm 0.17^{\mathrm{a}}$ \\
\hline SPD & $5.97 \pm 0.20^{\mathrm{b}}$ & $5.40 \pm 0.42^{\mathrm{a}}$ & $4.94 \pm 0.60^{\mathrm{ab}}$ \\
\hline SPM & $6.25 \pm 0.18^{\mathrm{b}}$ & $6.20 \pm 0.12^{\mathrm{b}}$ & $5.26 \pm 0.35^{\mathrm{b}}$ \\
\hline PUT & $6.44 \pm 0.35^{\mathrm{b}}$ & $6.41 \pm 0.07^{\mathrm{b}}$ & $5.14 \pm 0.19^{\mathrm{ab}}$ \\
\hline
\end{tabular}

*Standard deviation of average of three replications. Values followed by different letters are significantly different from each other $(P<0.05)$ according to Duncan’s test.

\section{Proline content}

Proline content significantly increased in the leaves treated with diuron (Table 4). For example, the increment in proline contents of the leaves treated with diuron, and compared to the control, were found to be $42.69 \%, 62.18 \%$ and $85.12 \%$ at 24,48 and

Table 4

Proline content of the leaves pretreated with polyamines and treated with diuron afterwards

\begin{tabular}{|l|c|c|c|}
\hline \multirow{2}{*}{ Treatments } & \multicolumn{3}{|c|}{$\begin{array}{c}\text { Proline content (mg/g fresh weight) } \\
\text { Hours after diuron treatment }\end{array}$} \\
\cline { 2 - 4 } & 24 & 48 & 72 \\
\hline Control & $1.78 \pm 0.09^{* \mathrm{a}}$ & $3.57 \pm 0.41^{\mathrm{a}}$ & $3.90 \pm 0.52^{\mathrm{a}}$ \\
\hline Diuron & $2.54 \pm 0.04^{\mathrm{b}}$ & $5.79 \pm 0.53^{\mathrm{cd}}$ & $7.22 \pm 0.50^{\mathrm{b}}$ \\
\hline SPD & $3.51 \pm 0.36^{\mathrm{c}}$ & $5.69 \pm 0.44^{\mathrm{c}}$ & $9.54 \pm 0.31^{\mathrm{c}}$ \\
\hline SPM & $4.30 \pm 0.24^{\mathrm{d}}$ & $4.56 \pm 0.23^{\mathrm{b}}$ & $8.80 \pm 1.04^{\mathrm{c}}$ \\
\hline PUT & $5.33 \pm 0.22^{\mathrm{e}}$ & $6.51 \pm 0.44^{\mathrm{d}}$ & $10.66 \pm 0.96^{\mathrm{d}}$ \\
\hline
\end{tabular}

*Standard deviation of average of three replications. Values followed by different letters are significantly different from each other $(P<0.05)$ according to Duncan's test. 
$72 \mathrm{hrs}$, respectively. Pretreatment with polyamines also significantly increased proline level of the leaves. It was found that especially PUT significantly increased proline content, compared with the leaves treated with diuron. At the end of experiments, proline amount in the leaves treated with diuron was $7.22 \mathrm{mg}$ per $g$ fresh weight whereas in the PUT-pretreated leaves it was $10.66 \mathrm{mg}$ per $g$ fresh weight. Also, proline level of the leaves pretreated with SPD and SPM was higher than that of unpretreated leaves after $72 \mathrm{~h}$ of diuron treatment.

\section{Enzyme activities}

SOD activity gradually increased after the leaves were treated with diuron but statistically significant increases were recorded at 48 and $72 \mathrm{hrs}$. It was found that the increment in the SOD activity in the leaves treated with diuron was $12.37 \%, 31 \%$ and $44.72 \%$ at 24,48 and $72 \mathrm{hrs}$ of treatment, respectively, compared to the control. Pretreatment with polyamines did not change significantly SOD activity at $24 \mathrm{~h}$ of diuron treatment in comparison with the leaves pretreated with water. At $48 \mathrm{~h}$ of diuron treatment, SOD activity in the leaves pretreated with polyamines was the same as in the control. At $72 \mathrm{~h}$ of diuron treatment, the activity was found to be $28.01,31.31$ and 18.2 U per mg protein in the leaves pretreated with SPD, SPM and PUT, respectively, while it was $26.5 \mathrm{U}$ per mg protein in the leaves treated with diuron (Fig. 2).

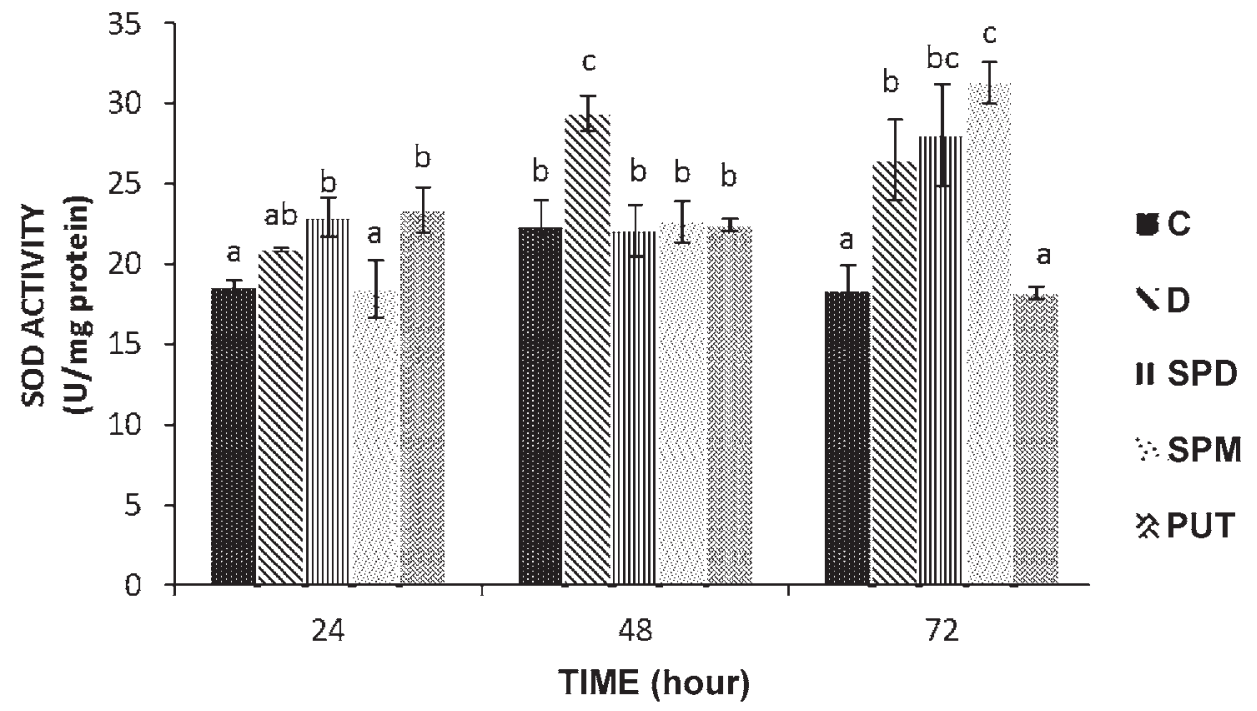

Fig. 2. SOD activity in maize leaves pretreated with polyamines and treated with diuron afterwards (C: Control, D: Diuron, SPD: Spermidine, SPM: Spermine, PUT: Putrescine). Vertical bars represent standard deviation of three samples. Within each hour, different letters indicate the differences among the means of three replicates. The differences between the means are significant at $P<0.05$ 
GPX activity did not change significantly in the leaves treated with diuron, compared to the control, at 24 and 48 hrs of treatment, but a statistically significant increase was recorded at $72 \mathrm{~h}$. Pretreatment with SPD increased GPX activity at $24 \mathrm{~h}$ of treatment but there was no significant change at $48 \mathrm{~h}$ and decreased at $72 \mathrm{~h}$. The change in GPX activity of the leaves pretreated with SPM was not statistically significant either, in comparison with the leaves treated with diuron. However, the increase in GPX activity in the leaves pretreated with PUT at $48 \mathrm{~h}$ was found to be statistically significant (Fig. 3).

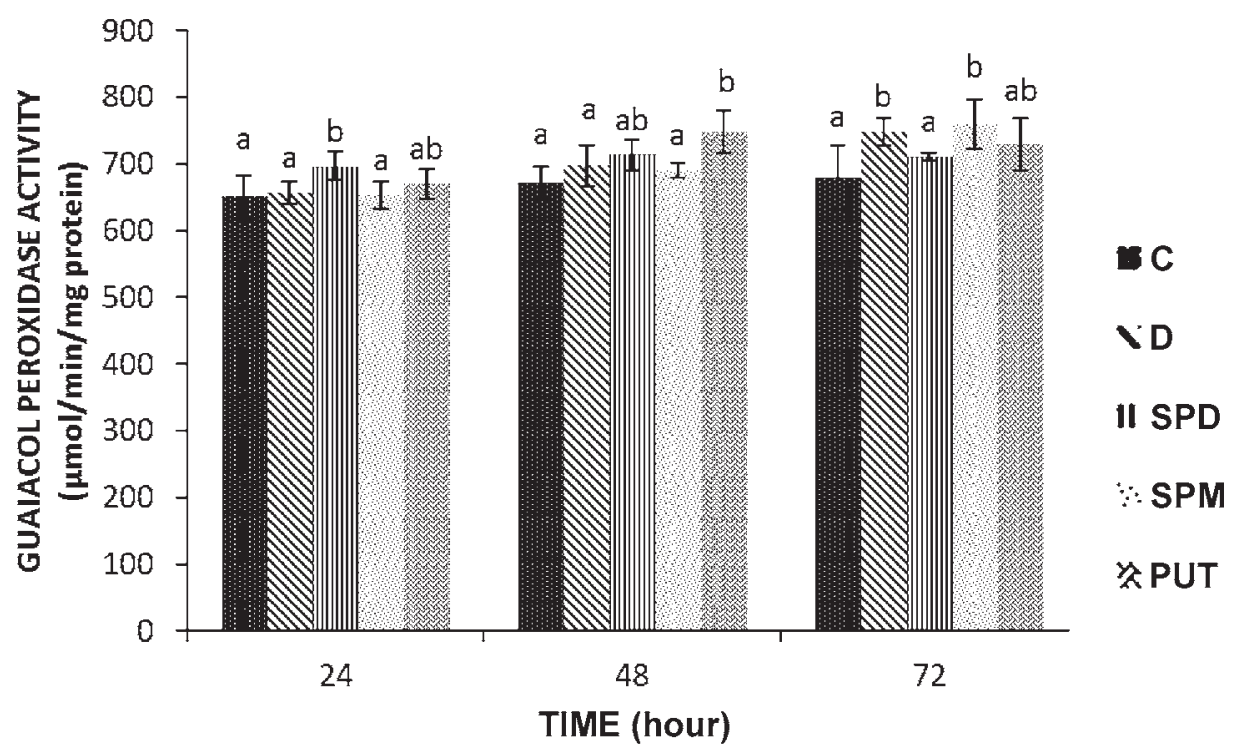

Fig. 3. Guaiacol peroxidase activity in maize leaves pretreated with polyamines and treated with diuron afterwards (C: Control, D: Diuron, SPD: Spermidine, SPM: Spermine, PUT: Putrescine). Vertical bars represent standard deviation of three samples. At each point of time, different letters indicate the differences among the means of three replicates. The differences between the means are significant at $P<0.05$

After diuron treatment, GR activity gradually increased. It was found that GR activity increased by $60.4 \%$ at $72 \mathrm{~h}$ of diuron treatment. Pretreatment with SPD significantly increased GR activity. Also, GR activity in the leaves pretreated with PUT increased but a statistically significant increase was recorded at $48 \mathrm{~h}$ as compared to that in the leaves treated with diuron.

Pretreatment with SPM had no significant effect on GR activity following only diuron treatment (Fig. 4).

CAT activity was not changed significantly in the leaves treated with diuron at 24 and $48 \mathrm{hrs}$ but it statistically decreased at $72 \mathrm{~h}$. This loss was found to be $28.42 \%$, compared to the control. Similarly, the same change was found in CAT activity of the leaves pretreated with SPD. Pretreatment with PUT and SPM significantly prevented the loss of CAT activity induced by diuron at $72 \mathrm{~h}$ (Fig. 5). 


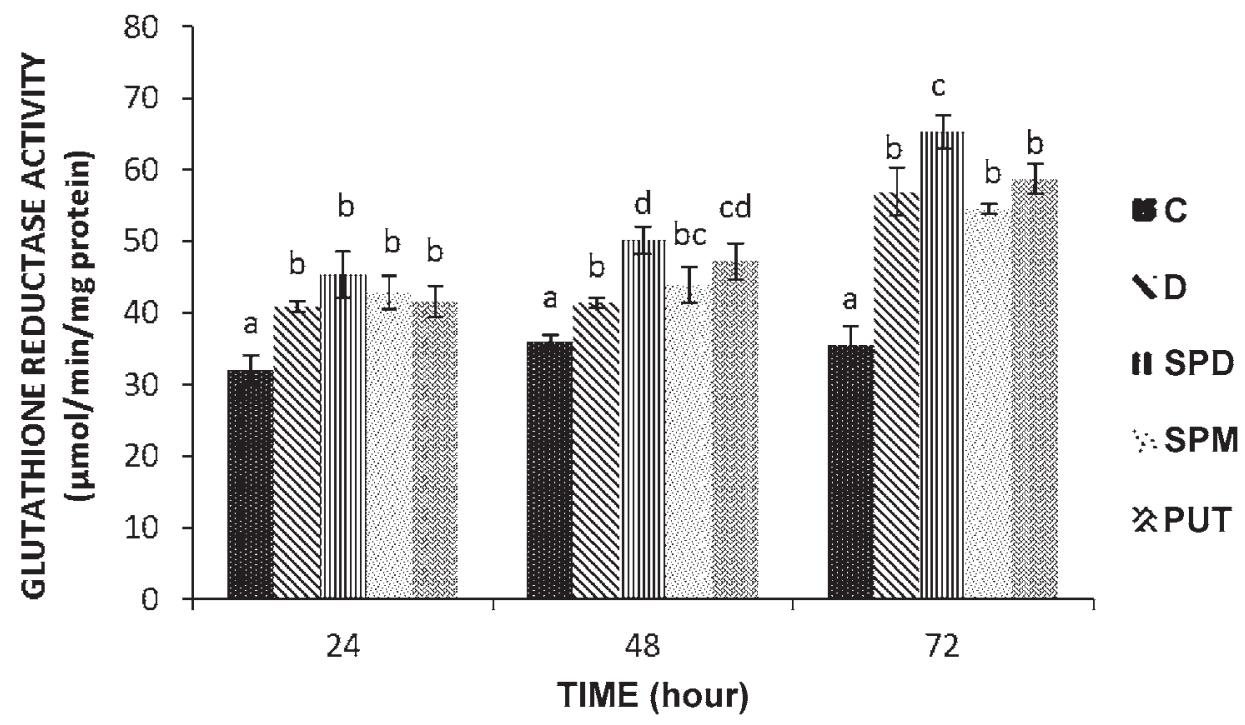

Fig. 4. Glutathione reductase activity in maize leaves pretreated with polyamines and treated with diuron afterwards (C: Control, D: Diuron, SPD: Spermidine, SPM: Spermine, PUT: Putrescine). Vertical bars represent standard deviation of three samples. Within each hour, different letters indicate the differences among the means of three replicates. The differences between the means are significant at $P<0.05$

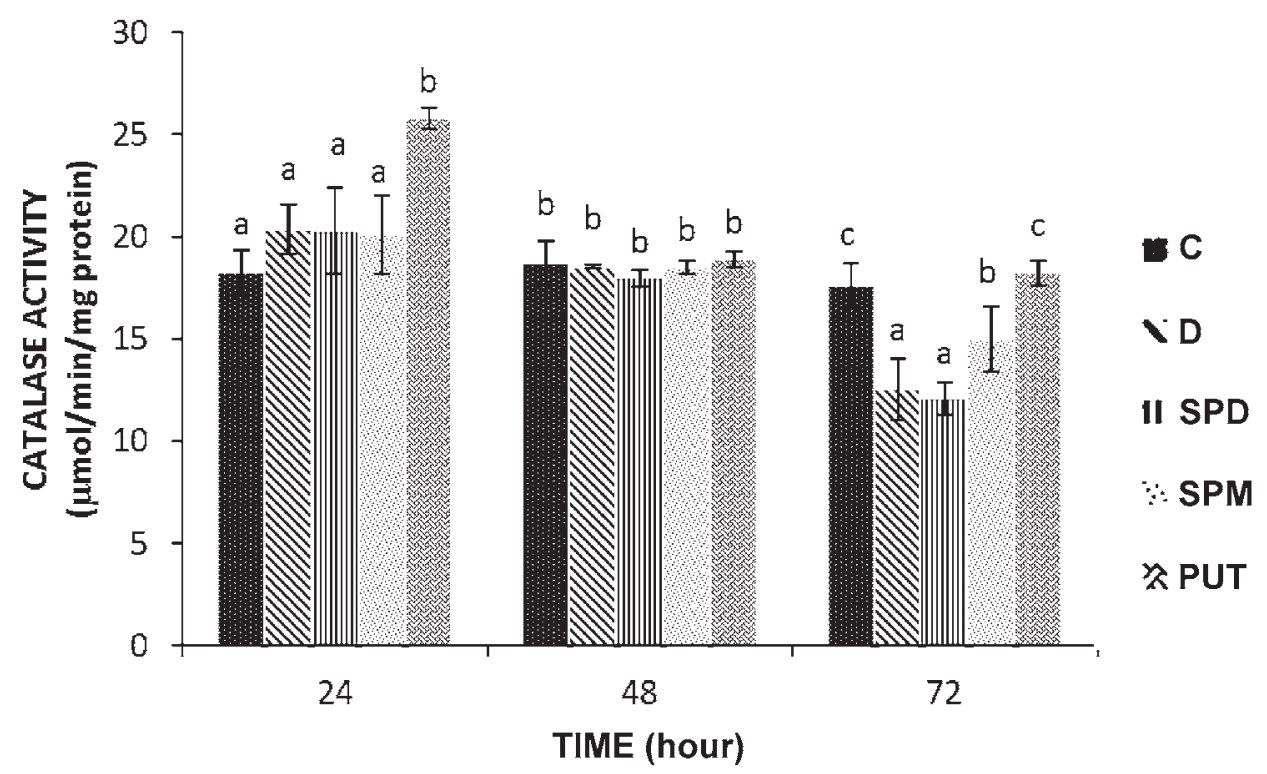

Fig. 5. Catalase activity in maize leaves pretreated with polyamines and treated with diuron afterwards (C: Control, D: Diuron, SPD: Spermidine, SPM: Spermine, PUT: Putrescine). Vertical bars represent standard deviation of three samples. Within each hour, different letters indicate the differences among the means of three replicates. The differences between the means are significant at $P<0.05$ 


\section{DISCUSSION}

In response to diuron, lipid peroxidation and proline contents of maize leaves significantly increased while photosynthetic pigments and soluble protein levels decreased. The accumulation of MDA was measured as a sign of lipid peroxidation because MDA is one of products of lipid peroxidation and the result of cell membrane injury [2, 45]. The increase in MDA content of maize leaves may be due to the increase in ROS levels induced by diuron. However, it has been reported in several studies that diuron affected the production of ROS [31, 35]. In the present study, MDA levels in the leaves pretreated with polyamines were found to be lower than those of leaves treated only with diuron. SPM was the most effective in preventing to lipid peroxidation. Benavides et al. [7] described that lipid peroxidation induced by paraquat was almost completely prevented by SPM in sunflower leaf discs. Also, Kitada et al. [26] reported that SPM was the most effective in inhibiting lipid peroxidation in rat liver microsomes due to direct binding to microsomal phospholipids, and Tadolini et al. [36] attributed the inhibition of lipid peroxidation by SPM and SPD to the formation of a polycation/phospholipid vesicle complex. The more pronounced protective effect of SPM, in comparison with SPD and PUT, could be accounted for its longer chain and greater number of positive charges which result in a more effective neutralizing and membrane stabilizing ability [41].

Previous studies have demonstrated that the reduction of chlorophyll content might be a good indicator for monitoring damage of the plant growth and development [24]. In this study, it was shown that chlorophyll was rather sensitive to diuron. Total chlorophyll content in the leaves treated with diuron was significantly reduced, compared to the control. We have also found that the reduction in total chlorophyll content induced by diuron was significantly prevented in the leaves pretreated with polyamines. SPM and SPD were the most effective in preventing total chlorophyll loss in maize leaves. However, SPM has been reported as the very polyamine which preserved the most thylakoid integrity in oat leaves [38] and SPD was the most effective in inhibiting chlorophyll loss induced by paraquat in sunflower leaf discs [7].

Carotenoid levels also significantly decreased in the leaves treated with diuron, similar to total chlorophyll loss. Similarly, Fayez [19] reported that carotenoid and chlorophyll contents of soybean leaves treated with diuron were significantly reduced. In the present study, the reduction of carotenoid content induced by diuron was significantly prevented in the leaves pretreated with polyamines. SPM and SPD were the most effective in inhibiting the losses of carotenoids in maize leaves. The increment in carotenoid contents in the leaves pretreated with polyamines can reduce diuron toxicity because carotenoids act as efficient quenchers of triplet chlorophyll and singlet oxygen [13]. Also, polyamines can act directly as free radical scavengers and reduce the damage of diuron on photosynthetic pigments. Moreover, polyamines reverted the effect of diuron on the level of soluble protein almost completely at $24 \mathrm{~h}$ of treatment, SPM and PUT was the most effective at $48 \mathrm{~h}$ and the effect of only SPM was significant at $72 \mathrm{~h}$ in preventing of soluble protein losses. Similarly, Unal et al. [39] reported that exogenously applied SPM samples showed higher protein concentration than other exoge- 
nously added SPD and PUT samples. Applications of SPD and SPM were effective in retarding the loss of D1, D2 and cytochrome $\mathrm{f}$ from the thylakoid membranes, as well as large Rubisco subunits and chlorophyll from the leaf tissue [9]. It was also reported that PUT, SPD and SPM are associated with light harvesting complex and PS II [27] and polyamines may protect photosystem II from UV-A radiation [39]. So, polyamines can protect PS II against diuron toxicity.

On the other hand, it was found that proline content significantly increased in the leaves treated with diuron. Similarly, proline content in the soybean leaves treated with diuron was recorded to be increased [19]. It is more probable that the proline increase reflected stress due to herbicide action. Due to its action as singlet-oxygen quencher and scavenger of $\mathrm{OH}$ radicals, proline is able to stabilize proteins, DNA and membranes [32]. In addition, it was reported that the damaging effects of singlet oxygen and hydroxyl radicals on PS II can be reduced by proline in isolated thylakoid membranes [3]. So, the increment in proline content of the leaves pretreated with polyamines can contribute to the role of free radical scavengers of polyamines and protect the plants against PS II inhibiting herbicide diuron.

SOD, GPX, GR and CAT play important roles in scavenging ROS and maintaining the physiological redox status of organisms [12]. In the present study, SOD activity significantly increased in the leaves treated with diuron for, respectively, 48 and $72 \mathrm{~h}$. Similarly, increases in SOD activity have been observed in response to treatment with herbicides paraquat, diquat, diuron, atrazine and prometryne [17, 18, 24, 33]. In the present study, the effects of polyamines on SOD activity were different according to the polyamine tested and time after diuron treatment. Polyamines prevented the increase in SOD activity induced by diuron at $48 \mathrm{~h}$ of treatment but SPD and SPM increased the enzyme activity at $72 \mathrm{~h}$ of treatment. It was suggested that polyamines were implicated in direct scavenging of free radicals [30,38], thereby SOD activity cannot be increased at $48 \mathrm{~h}$ of treatment.

In the present study, diuron caused significant changes in the activity of $\mathrm{H}_{2} \mathrm{O}_{2}$ scavenging enzymes. A decrease of CAT activity and an increase of GPX activity in the leaves treated with diuron at $72 \mathrm{~h}$ of the treatment as compared to the control were observed. Similarly; Kubis [30] reported that GPX activity increased in water stressed cucumber leaves while CAT activity decreased. Moreover, GPX activity was poorly stimulated in Lemna minor treated with diuron and even inhibited when exposure exceeded $48 \mathrm{~h}$, while CAT activity was inhibited by the lowest concentration of diuron and at the shortest $(6 \mathrm{~h})$ time exposure [37]. On the other hand, no significant change of CAT activity was observed in Scenedesmus obliquus treated with diuron [21]. To test whether exogenously applied polyamines could protect the plants by affecting GPX and CAT activity against diuron toxicity, the change in activities of the enzymes was determined in the leaves pretreated with polyamines in the present study. Pretreatment with SPD increased GPX activity at $24 \mathrm{~h}$ of the treatment but decreased at $72 \mathrm{~h}$ compared with the leaves pretreated with water while significant change in CAT activity was not observed. Pretreatment with SPM did not change GPX activity during the whole series of experiments, in comparison with the leaves pretreated with water while it restored significantly the decrease in CAT activity induced by diuron. Pretreatment with PUT 
increased GPX activity at $48 \mathrm{~h}$ of the treatment and CAT activity at $24 \mathrm{~h}$ of the treatment, while the decrease in CAT activity induced by diuron at $72 \mathrm{~h}$ of the treatment was completely prevented by PUT. There are both similar and different results in the literature referring to the effects of polyamines on the activities of both enzymes under various stress coditions. For example, pretreatment with SPD induced a significant decrease in the activity of both enzymes in barley leaves under water deficit [29], while the decrease of CAT activity was substantially reduced but a higher increase of GPX activity was induced by SPD in water-stressed cucumber leaves [30]. Zhang et al. [44] reported that exogenous application of PUT and SPD could effectively prevent cucumber seedlings from chilling injury by inducing activities of several antioxidant enzymes including SOD, GPX, APX and CAT.

In addition to SOD, GPX and CAT activities, a change of GR activity was also detected in the present study. It was found that GR activity gradually increased in the leaves treated with diuron during the whole experiment. This result was in accordance also with earlier results on Lemna minor and Scenedesmus obliquus treated with diuron $[21,37]$. It is probable that the increase in GR activity under stress conditions is to provide GSH for ascorbate-glutathione pathway and to maintain a high ratio of GSH/ GSSG. Pretreatment with SPD increased GR activity during the experiment, SPM did not change significantly GR activity and PUT increased the enzyme activity at $48 \mathrm{~h}$ of the treatment in comparison to the leaves pretreated with water. Similar to our results, Kubis [28] reported that GR activity increased in the barley leaves pretreated with SPD before water stress, and Verma \& Mishra [42] recorded that pretreatment with PUT increased GR activity in salt stressed Brassica juncea. It is suggested that GR activity elevated by polyamines increase the ratio of $\mathrm{NADP}^{+} / \mathrm{NADPH}$, thereby ensuring the availability of $\mathrm{NADP}^{+}$to intercept electrons resulting in lower flow of electron to $\mathrm{O}_{2}$ for generating ROS. As it is shown, polyamines are able to moderate the activities of scavenging system enzymes and thus influence the ROS level.

In conclusion, this is the first report examining the protective effect of polyamines against diuron damage in plants and our data show that pretreatment with polyamines reduce diuron toxicity at different degrees according to the polyamine and/or the tested parameter.

\section{ACKNOWLEDGMENT}

This work was supported by the Research Fund of Recep Tayyip Erdogan University, Rize, Turkey (project number: 2009.102.03.1).

\section{REFERENCES}

1. Aebi, H. (1983) Catalase. In: Bergmeyer, H. (ed.) Methods of Enzymatic Analysis. Vol. 3, pp. 273-277.

2. Akbulut, G. B., Yiğit, E. (2010) The changes in some biochemical parameters in Zea mays cv. "Martha F1" treated with Atrazine. Ecotoxicology and Environ. Safety 73, 1429-1432.

3. Alia Saradhi, P. P., Mohanty P. (1997) Involvement of proline in protecting thylakoid membranes against free radical-induced photodamage. J. Photochem. Photobiol. 38, 253-257. 
4. Altman, A. (1982) Retardation of radish leaf senescence by polyamines. Physiol. Plant. 54, 189-193.

5. Arnon, D. I. (1949) Copper enzymes in chloroplasts, polyphenoloxidase in Beta vulgaris. Plant Physiol. 24, 1-15

6. Bates, L. S., Waldren, R. P., Teare, I. D. (1973) Rapid determination of free polin for water stress studies. Plant and Soil 39, 205-207.

7. Benavides, M. P., Gallego, S. M., Comba, M. E., Tomaro, M. T. (2000) Relationship between polyamines and paraquat toxicity in sunflower leaf discs. Plant Growth Regulation 31, 215-224.

8. Beauchamp, C., Fridovich, I. (1971) Superoxide dismutase: improved assays and an assay applicaple to acrylamide gels. Anal. Biochem. 4, 276-287.

9. Besford, R. T., Richardson, C. M., Campos, J. L., Tiburcio, A. F. (1993) Effect of polyamines on stabilisation of molecular complexes of thlykoid membranes of osmotically stressed oat leaves. Planta 186, 201-206.

10. Bors, W., Langebartels, C., Michel, C., Sandermann, H. (1989) Polyamine as radical scavengers and protectants against ozone damage. Phytochemistry 28, 1589-1595.

11. Bradford, M. (1976) Rapid and sensitive method for the quantification of microgram quantities of protein utilizing the principle of protein dye binding. Anal. Biochem. 72, 248-254.

12. Cho, U. H., Seo, N. H. (2005) Oxidative stress in Arabidopsis thaliana exposed to cadmium is due to hydrogen peroxide accumulation. Plant Sci. 168, 113-120.

13. Demming-Adams, B. (1990) Carotenoids and photoprotection in plants: a role for the Xanthophyll Zeaxanthin. Biochem. Biophys. Acta 1020, 1-24.

14. Dhindsa, R. S., Matowe, W. (1981) Drought tolerance in two mosses: correlated with enzymatic defense against lipid peroxidation. J. Exp. Bot. 32, 79-91.

15. Drolet, G., Dumbroff, E. B., Legge, R. L., Thompson, J. E. (1986) Radical scavenging properties of polyamines. Phytochem. 25, 367-371.

16. Duan, J., Li, J., Guo, S., Kang, Y. (2008) Exogenous spermidine affects polyamine metabolism in salinity-stressed Cucumis sativus roots and enhances short-term salinity tolerance. J. Plant Physiology 165, 1620-1635.

17. Durmuş N., Kadıŏlu, A. (2005) Spermine and putrescine enhance oxidative stress tolerance in maize leaves. Acta Physi. Plant. 27, 515-522.

18. Durmuş N., Kadıŏglu, A. (2005) Reduction of paraquat toxicity in maize leaves by benzyladenine. Acta Biol. Hung. 56, 97-107.

19. Fayez, K. A. (2000) Action of photosynthetic diuron herbicide on cell organelles and biochemical constituents of the leaves of two soybean cultivars. Pest. Biochem. Physi. 66, 105-115.

20. Foyer, C. H., Halliwell, B. (1976) The presence of glutathione and glutathione reductase in chloroplasts: A proposed role in ascorbic acid metabolism. Planta 133, 21-25.

21. Geoffroy, L., Teisseire, H., Couderchet, M., Vernet, G. (2002) Effect of oxyfluorfen and diuron alone and in mixture on antioxidative enzymes of Scenedesmus obliquus. Pest. Biochem. Physiol. 72, 178 185.

22. Heath, R. L., Packer, L. (1968) Photoperoxidation in isolated chloroplast. I. Kinetics and stoichiometry of fatty acid peroxidation. Arch. Biochem. Biophys. 125, 189-198.

23. Jaspars, E. M. J. (1965) Pigmentation of tobacco crown-gall tissues cultured in vitro in dependence of the composition of the medium. Physiol. Plant. 18, 933-940.

24. Jiang L., Yang H. (2009) Prometryne-induced oxidative stres and impact on antioxidant enzymes in wheat. Ecotoxicology Environ. Safety 72, 1687-1693.

25. Jordanov, I., Goltsev, V., Kruleva, I. (1990) Protective effect of putrescine and spermidine on the thylakoid membrane activity after high temperature treatment. In: Alscheffsky, M. (ed.), Current Research in Photosynthesis, IV. Kluwer Academic Publishers, the Netherlands, pp. 699-703.

26. Kitada, M., Igarashi, K., Hirose, S., Kitagawa, K. (1979) Inhibition by polyamines of lipid peroxide formation in rat liver microsomes. Biochem. Biophys. Res. Com. 87, 388-394.

27. Kotzabasis, K., Fotinon, C., Roubelakis-Angelakis, K. A., Ghanotakis, D. (1993) Polyamines in the photosynthetic apparatus. Photosystem II highly resolved subcomplexes are enriched in spermine. Photosynth. Res. 38, 83-88.

Acta Biologica Hungarica 66, 2015 
28. Kubis, J. (2001) Polyamines and "scavenging system": Influence of exogenous spermidine on HalliwellAsada pathway enzyme activity in Barley leaves under water deficit. Acta Physiol. Plant. 23, 335-341.

29. Kubis, J. (2003) Polyamines and "scavenging system": Influence of exogenous spermidine on catalase and guaiacol peroxidase activities, and free polyamine level in Barley leaves under water deficit. Acta Physiol. Plant. 25, 337-343.

30. Kubis, J. (2008) Exogenous spermidine differentially alters activities of some scavenging system enzymes, $\mathrm{H}_{2} \mathrm{O}_{2}$ and superoxide radical levels in water-stressed cucumber leaves. J. Plant Physiol. 165, $397-406$.

31. Kumar, K. S., Choo, K., Yea, S. S., Seo, Y., Han, T. (2010) Effects of the phenylurea herbicide diuron on the physiology of Saccharina japonica aresch. Toxicol. Environ. Health Sci. 2, 188-199.

32. Matysik, J., Alia Bhalu, B., Mohanty, P. (2002) Molecular mechanisms of quenching of reactive oxygen species by proline under stress in plants. Curr. Sci. 82, 525-532.

33. Nemat Alla, M. M., Hassan, N. M. (2006) Changes of antioxidants levels in two maize lines following atrazine treatments. Plant Physiol. Biochem. 44, 202-210.

34. Ormrod, D. P., Beckerson, D. W. (1986) Polyamines as antiozonants for tomato. Hort. Sci. 21, 1070 1071.

35. Reis, M. O., Necchi, J. O., Colepicolo, P., Barros, M. P. (2011) Co-stressors chilling and high light increase photooxidative stress in diuron-treated red alga Kappaphycus alvarezii but with lower involvement of H2O2. Pest. Biochem. Physiol. 99, 7-15.

36. Tadolini, B., Cabrini, L., Landi, L., Varani, E., Pasquali, P. (1984) Polyamine binding to phospolipid vesicles and inhibition of lipid peroxidation. Biochem Biophys. Res. Com. 122, 550-555.

37. Teisseire, H., Vernet, G. (2000) Is the "Diuron Effect" due to herbicide strengthening of antioxidative defenses of Lemna minor. J. Exp. Bot. 66, 153-160.

38. Tiburcio, A. F., Besford, R. T., Capell, T., Borrell, A., Testillano, P. S., Risueno, M. C. (1994) Mechanism of polyamine action during senecence responses induced by osmotic stress. J. Exp. Bot. 45, 1789-1800.

39. Unal, D., Tuney, I., Sukatar, A. (2008) The role of external polyamines on photosynthetic responses, lipid peroxidation, protein and chlorophyll a content under the UV-A (352 nm) stres in physcia semipinnata. J. Photochem. Photobiol. B: Biol. 90, 64-68.

40. Urbanek, H., Kuzniak-Gebarowska, E., Herka, K. (1991) Elicitation of defense responses in bean leave by Botrytis cinerea polygalacturanase. Acta Physiol. Plant. 13, 43-50.

41. Velikova, V., Yordanov, I., Edreva, A. (2000) Oxidative stress and some antioxidant systems in acid rain-treated bean plants, protective role of exogenous polyamines. Plant Scien. 151, 59-66.

42. Verma, S., Mishra, S. N. (2005) Putrescine alleviation of growth in salt stressed Brassica juncea by inducing antioxidative defense system. J. Plant Physiol. 162, 669-677.

43. Wi, S. J., Kim, W. T., Park, K. Y. (2006) Overexpression of carnation SAdenosylmethionine decarboxylase gene generates a broad-spectrum tolerance to abiotic stresses in transgenic tobacco plants. Plant Cell Rep. 25, 1111-1121.

44. Zhang, W., Jiang, B., Li, W., Song, H., Yu, Y., Chen, J. (2009) Polyamines enhance chilling tolerance of cucumber (Cucumis sativus L.) through modulating antioxidative system. Scientia Hort. 122, 200-208.

45. Zhao, H., Yang, H. (2008) Exogenous polyamines alleviate the lipid peroxidation induced by cadmium chloride stress in Malus hupehensis Rehd. Scientia Horticulturae 116, 422-447. 